Published as:

Hyland KL Faculty feedback: Perceptions and practices in L2 disciplinary writing., Journal of Second Language Writing, 2013, v. 22(3) p. 240-253

\title{
Faculty feedback: perceptions and practices in L2 disciplinary writing
}

\section{Ken Hyland}

\section{University of Hong Kong}

\begin{abstract}
While a great deal of the research on feedback given to second language writers focuses narrowly on what goes on in language classrooms, most of the writing that matters to undergraduates occurs in disciplinary contexts. Students are attending academic writing courses to more effectively participate in the debates of their disciplines and to demonstrate their learning to readers in those disciplines. They are 'Writing to Learn' rather than 'Learning to Write', yet we often know little about the advice faculty give to students or what they are trying to achieve through their feedback. The study seeks to move L2 writing feedback studies beyond the texts produced for teachers in the writing classroom while contributing to our understanding of students attempts to write themselves into their disciplines. Drawing on interviews with 20 teachers from four faculties at an English medium university in Hong Kong, I explore their perceptions of feedback to illuminate students' experiences of disciplinary writing. Overall, the findings show that faculty teachers' feedback is shaped by a desire to see students to write in disciplinary approved ways, yet only infrequently supports students towards this goal.
\end{abstract}

Keywords: disciplinary writing; feedback; tutor perceptions; higher education; academic literacy 


\section{Faculty feedback: perceptions and practices in L2 disciplinary writing}

\section{Introduction}

While feedback is widely seen as potentially one of the most powerful influences on learning, rated just below direct instruction and students' cognitive abilities (Hattie \& Timperley, 2007), this potential often remains unrealised. Certainly, by providing writers with a sense of audience and an understanding what readers' value in a text, teacher feedback should play an important role in scaffolding cognitive development, alerting students to their strengths and weaknesses, and contributing to their acquisition of disciplinary subject matter and writing conventions. Educational evidence, however, questions the effectiveness of feedback in disciplinary studies (e.g. Price, Handley, Millar \& O’Donovan, 2010) with significant student dissatisfaction revealed in student surveys in the UK, Australia and Hong Kong (Krause et al, 2005; Carless, 2006).

This ambivalence is echoed by those working in the field of second language writing where debates have become mired in inconclusive disputes around the effectiveness of error correction (Ferris, 2006; Truscott, 2009) and an exclusive focus on the improvement of 'writing', understood as students' composing competencies and finished texts. In most higher education contexts, however, students are not attending academic writing courses in order to learn to "write", or even to write in some abstractly academic way; they are learning to write for purposes which lay outside the English class. For them, writing is a tool they need in order to participate in their disciplines and to demonstrate their learning to readers in those disciplines. Writing therefore contributes to learning in areas other than writing itself: instruction, and feedback, relate to the acquisition of an academic competence in both disciplinary knowledge and the ability to discuss it appropriately.

This aspect of feedback has not always been sufficiently recognised in the literature, however, and I address this gap here by exploring what writing and feedback mean to 20 members of four faculties working at an English medium university in Hong Kong. My purpose is to illuminate a largely 
neglected area of second language writing and to reveal something of the disciplinary preferences and proclivities of this instructional context. So while the potential value of this study lies in its contribution to writing in the disciplines scholarship with its focus on feedback, it also has something to say about feedback with a "Writing-to-Learn" dimension of L2 writing, in contrast to the "Learning-to-Write" side which is explored in most of the feedback literature. Ultimately, however, I hope that a better understanding of what faculty teachers' intentions are in setting written assignments and providing feedback may give writing teachers insights into the demands disciplinary writing makes on their students and perhaps use these understandings to inform their own teaching.

\section{Writing in the disciplines}

Students do many different kinds of writing at university (e.g. Nesi \& Gardner, 2011) and most of it that matters to them in terms of their GPA, occurs in subject disciplines. This kind of writing can often take a very different form to that which goes on in writing classes, evoking a distinction made recently by Manchón (2011a) between Learning-to-Write (LW), where students are learning to express themselves in writing, and Writing-to-Learn (WL), where they are using writing to develop their expertise in a particular area, in this case, the content of the discipline. This is the way students learn to display their critical and analytic skills, their use of English for reasoning and persuasion, their grasp of subject matter issues, and their ability to shape an argument using the conventions of their field. This is an important distinction to make for, as Manchón (2011b, p. 3) observes, the two approaches "have developed almost independently from each other, have been informed by different theoretical frameworks, and have resulted in different pedagogical procedures".

The ability to construct disciplinary arguments is at the heart of conceptual understanding of a field and this means that students must learn to craft their writing in community-specific ways. Learners are required to think their way into their disciplines through writing, and professors across the curriculum seek to initiate students into these particular styles of thinking by setting specific writing assignments (e.g. Currie, 1993). Instruction in the concepts and content of a subject involves 
familiarizing students with the norms, expectations and conventions of writing of that interpretive community and this social and epistemological diversity is therefore the context in which second language students experience writing at university. Written genres themselves become the tools by which knowledge and learning are articulated for students (English, 2011). Because of this, writing has come to be seen as a social practice rather than a skill (Lillis, 2001) and specific genres are recognised as having a powerful influence on how students understand and engage with their disciplines. Disciplinary discourses are, in fact, systematic expressions of institutional meanings and values which are communicated to students along with the texts they are asked to read and write.

University writing teachers are therefore often faced with complex instructional contexts in which they must respond to the ways learners are expected to write outside their language classes. As a result, they have become increasingly sensitive to the ways genres are written, used and responded to in different disciplines (e.g. Hyland, 2004; Hyland \& Bondi, 2006). Even in cognate fields, such as nursing and midwifery, students are asked to produce very different writing assignments (Gimenez, 2009) and this diversity of disciplinary writing can present considerable challenges to students (e.g. Leki, 2007; Sternglass, 1997). A recent large scale corpus study, in fact, has distinguished thirteen "genre families", ranging from case studies through empathy writing to research reports, which differ in social purpose, generic stages and the networks they form with other genres (Nesi \& Gardner, 2011). Writing teachers have therefore sought to draw on the knowledge learners bring to the class from their content courses.

A Writing-to-Learn perspective, then, sees writing as a mode of learning, of both content and the way to talk about that content, which means that teaching should account for the knowledge learners already possess and be situated in the context in which it is used. This view emerges from the traditions of Content-Based Instruction (CBI) and, in the European context, Content and Language Integrated Learning (CLIL). While the research has produced some rich pictures of the struggles of individual writers as they operate in content areas, this is not a large literature and it is mainly 
confined to work in the United States (see review in Hirvela, 2011). Nor has it tended to address the perceptions of faculty teachers or examined the importance of feedback in this learning.

These approaches, to varying degrees, recognise that writing operates as a tool for learning both disciplinary content and the specialized conventions of disciplinary discourse. So while undergraduates must learn to process new content when writing, they must also learn to critically discuss this content with authority (Ortega, 2011). The notion of Writing-to-Learn therefore reminds us that the writing which students do in their English classes, and the feedback they receive on it, does not occur in a vacuum but rather within a layered hierarchy of interrelated goals, purposes and experiences. Most feedback research, however, has been conducted in Learning-to-Write contexts which tend to focus on locale-specific, and often experimental, writing tasks isolated from students' wider experiences of university study (e.g. Bitchener \& Knoch, 2009; Ferris \& Roberts, 2001; Truscott \& Hsu, 2008). As a result, many writing tasks and a great deal of feedback in EAP classes fails to help students understand the connections between genre features and the possibilities for creating meanings in different fields (Wardle, 2009).

A key way in which faculty teachers communicate their expectations to learners is through responses to their assignments, yet we know very little about the advice faculty give students in this way or what they are trying to achieve. What do they focus on in their feedback? What is it they are looking for? This study addresses these questions and seeks to explore what faculty teachers set out to do in giving written assignments and in providing feedback on student responses to those assignments. While the concerns of writing teachers are not identical to those of faculty teachers, the answers to these questions might help strengthen our knowledge of faulty practices to better understand our students' writing needs. This, in turn, may enable us to better address those issues which students find most problematic about writing in the disciplines. 


\section{Methods: Setting, participants, and procedures}

a) Setting. The study takes place in a leading Hong Kong research-intensive university listed in the QS rankings as 23rd in the world and the first in Asia (http://www.topuniversities.com/universityrankings/world-university-rankings/2012). The university has some 25,000 students studying in 10 faculties through the medium of English. Although a research-focused university, teaching is highly valued and institutionally supported, both by core credit-bearing English for academic purposes programmes in the first and second years and by a range of professional development courses for staff, compulsory accreditation programmes, student evaluation surveys and a range of other quality assurance mechanisms.

While Cantonese is the first language of most undergraduates, Hong Kong universities use English as their medium of instruction and students are expected to engage competently in their studies and produce a range of genres of assessed written work in this language. Because students are accepted into a disciplinary programme on admission, an immediate connection is established between writing and community acculturation so that writing as a tool for learning content is integral to the undergraduate experience. More generally, the standard of English in Hong Kong, and the ability of graduates to use it effectively, is an issue of considerable concern to the wider community and regularly discussed in the press.

The majority of students, however, will have attended Chinese medium secondary schools and have achieved middling levels of proficiency in the language. The emphasis at these schools is largely on equipping students with good understanding of grammar and a reasonable level of communicative ability. As in many countries, new students are largely unprepared for either the kinds of writing that will be expected of them or the greater independence that is afforded them at university. Their predegree preparation has not included the kind of extensive writing practice they will need nor familiarity with the relevant genres, placing a heavier burden on students, EAP teachers and subject faculty. 
b) Participants: The study is based on interviews with twenty academics, five from each of four faculties (Business, Science, Engineering and Arts) comprising some eight disciplines. Eleven teachers were Cantonese first language speakers and the rest were native English speakers from the United States, Australia and the UK, holding positions ranging from Assistant to full Professors. The participants in the study were all highly competent users of English with doctoral degrees from overseas institutions and all had held teaching positions for at least three years, with experience of teaching second language students in Hong Kong for at least two years. The participants were all teachers of first or second year undergraduate courses and volunteered for the study following an email recruitment shot to some 50 members in these four faculties. From those who indicated a willingness to participate, an equal number were selected from the four target faculties by random ballot. Informed consent was sought (in writing) from all academics prior to the data collection, and participants were assured of anonymity.

While generally hired for their research productivity, the academics were nevertheless aware of the culture of effective instruction at the university and were very conscious of representing themselves as effective teachers. Many of them acknowledged the provision of feedback as an aspect of this.

c) Procedures: The study adopted a heuristic and qualitative approach to data collection and analysis. Each faculty teacher was interviewed twice to uncover his or her experiences of teaching second language students, their attitudes to academic writing, the type and frequency of feedback they gave and what they wanted to achieve with it. Both interviews had a semi-structured format with open-ended prompts guided by the following questions:

1. What did tutors expect students to learn from their writing assignments?

2. What were tutors' feedback practices?

3. What value did they believe feedback has in learning?

4. How did they expect students to respond to their feedback?

5. What did they expect students to learn from their feedback? 
All interviews and discussions were digitally recorded, transcribed and entered into NVivo. An emergent analysis was carried out on the interview data, identifying recurring, developing and significant patterns and themes. The analysis therefore involved moving from 'individual stories to common elements' (Polkinghorne, 1995,p. 12).

The method seeks to make explicit the tacit knowledge or strategies that participants bring to their teaching. While the questions encourage them to reconstruct motivations and evaluate effectiveness, it is possible that the particular interview situation and the nature of the topic may influence the kinds of opinions produced in the interviews. Faculty are aware of the expectations on them to teach well in English and my presence as a language professional may have coloured their responses (the "Hawthorne effect"). To investigate the correspondence between faculty teachers' self-reports and their actual practices, I also collected 20 papers from students in the classes of the faculty teachers in four of the disciplines studied. The feedback on these texts was coded according to the focus of the feedback (content, language, academic conventions, format) by a graduate research assistant and myself (inter-rater reliability of kappa 0.8).

\section{Writing purposes and writer problems}

Irrespective of discipline, all teachers set written assignments as (often the only) assessment in their courses. This is the principal means of establishing a visible and measurable form of quality control while developing skills of disciplinary appropriate description, argument and critique. A key aspect of disciplinary acculturation involves the gradual acquisition of both the socially recognised conventions of writing and the established practices of knowledge construction. Several of my respondents mentioned this Writing-to-Learn connection explicitly:

Writing is absolutely key, it embodies the discipline: the main discipline product. Teaching History is about teaching students to write, or it has been hitherto. What I expect them to gain ultimately, as well as the ability to express themselves, is the ability to engage more effectively with discourses in the past. You can't do that unless you can articulate precisely what the discourse means.

(History) 
I think writing is very important. It reflects the ways which students structure and express their thoughts. So, I am less concerned about correct spelling and grammar, what I am very concerned about is teaching them to write logical essays which take a research question and address it in a structured and thoughtful way with evidence and logical conclusions.

(Business)

I want them to learn how to write in a scientific method. I want them to think logically and I want them to use the scientific protocol and express that through their writing. If they are going to continue in the biological field, they will be required to do these sorts of work; to write in a scientific style and format.

(Biology)

I would say the most important thing to learn is the conventions of argument. The students need to learn how to write a persuasive argument, providing evidence to support their arguments, evidence that has been obtained through reasonably good research. What is less important for me is creativity.

(Economics)

Interestingly, this concern with the rhetorical, genre level features of argument and disciplinary persuasive logic, rather than grammatical accuracy, reflects current approaches to academic writing instruction (e.g. Belcher, 2009; Hyland, 2006; Ravelli \& Ellis, 2004).

Disciplinary expectations therefore place constraints on student writing and provide a context for the tutors' feedback and evaluations of that writing. Another important aspect of this context, of course, is the fact that students are writing in a second language, although this was mentioned far less often by tutors, and was often treated as only a minor issue:

If they have problems with language errors, that means they are not working hard enough. They are 21 years olds. I mean they should have a high level of ability already, not just what they have learnt since coming here. When I assess their writing I have to treat everybody equally so grade grammar less, a very small percentage, maybe $5 \%$. If we 
focus on the content that puts everybody on the same playing field.

(Engineering)

Their language is not good, everyone is aware of that. I think the big problem is that many students think that to write scientific English they need to use very long words and very complex sentences. I always tell them keep it simple. It's like telling a story and you have to look after the readers.

(Biology)

While teachers recognised the difficulties students had in gaining control over disciplinary writing conventions, they were more likely to blame their lack of experience in the genre or their naivety in using academic English than their L2 backgrounds. Simply, many recognised that students' prior learning experiences could not provide them with the skills required to successfully develop the kinds of elaborated arguments and expositions which are set as assignments. This was typically attributed to the school system:

I found when students come in, organizing and making a clear argument was in fact pretty weak. Most of them haven’t experience writing or reading reports when they are in high school.

(Biology)

The biggest problem is they are not responsible for every sentence they write. Maybe this is the writing they do in school? But it is very important that every sentence is evidence for Engineering or professional writing, like in a court. But they write it not to the point. That is not good technical writing.

(Engineering)

It has nothing to do with not speaking English as a first language. My American students also have trouble. We are just asking them to write in a way they haven't seen before.

There is then, an expectation that students will write competently: learning the conventions of the discipline together with the conventions of discourse. Along with this, however, there is a 
recognition that many students are far from achieving this goal as they are hindered by a lack of familiarity with disciplinary writing and by the fact they are writing in a second language.

\section{Feedback focus and pedagogic purposes}

These various disciplinary contexts require different genres and demand different skills and this in turn suggests that faculty might focus on different aspects of students' writing in their feedback. Interestingly, despite the perception of many English teachers that faculty are only interested in students' knowledge of content, only two respondents explicitly mentioned this:

I don't set writing tasks hoping that they would improve their English writing. I want a paper about marketing research, about consumer behaviour, whatever. They need to conduct a project and they will write a report based on their research.

(Business)

Yes, I specify they have to minimize their errors but I focus on the content. You need to have your research finding here, your recommendation and your reason involved, a company description, research method, result these things, it's content-based. (Engineering)

As the second extract suggests, however, it is often difficult to distinguish between 'content', understood as the concepts, procedures, theories and understandings of a discipline, and 'form', or the rhetorical presentations of these in ways that will impress insiders.

Despite a pedagogic tradition which stretches back to Aristotle's distinction between logos (the logical content of a speech) and lexis (the style and delivery of a speech), many of these tutors seemed to recognise that this is an artificial and conditional divide. While not articulating this explicitly, faculty members generally acknowledged in their responses that language is not merely a mechanistic device for transcribing or delivering thought - it also has a profound effect on how it is received. This is why it is never possible to ever express exactly the same meaning using different forms; rhetorical choices carry meanings which are community-specific and which function to either 
bring together or disconnect discourse participants. The importance of disciplinary argument conventions lies in the fact that texts are the product of negotiations in which the writer is seeking to persuade the reader of both a line of reasoning and the competence of the writer. Put most simply: the way a student expresses his or her ideas is inseparable from the ideas themselves.

The fusion of form and content is often reflected in the actual comments made by teachers in their feedback on student papers. Table 1 shows that while there are disciplinary variations in what they chose to focus on in their comments, faculty teachers do not ignore language in their feedback.

Table 1: Distribution of tutor comments on student assignments (\%)

\begin{tabular}{lcccccc}
\hline Discipline & Content & Language & Argument & Format & Style & Totals \\
\hline Biology & 59.6 & 24.6 & 10.4 & 4.4 & 1.0 & 100 \\
Engineering & 39.5 & 27.5 & 26.3 & 4.2 & 2.5 & 100 \\
Business & 29.9 & 38.6 & 27.9 & 1.8 & 1.8 & 100 \\
History & 12.0 & 42.7 & 40.4 & 2.1 & 2.9 & 100 \\
Totals & 35.3 & 33.3 & 26.2 & 3.1 & 2.1 & 100 \\
\hline
\end{tabular}

About a third of the overall comments in this, admittedly small, corpus of 100 texts related to surface level language features such as circling errors, adding tense markers, admonishing students to use the passive, and so on. The more discursive humanities and social science fields tended to offer more explicit commentary on language issues:

My edit here is a classic example of the clarity that can be achieved if you adopt a SubjectVerb-Object sentence structure. Check your original and see how this expresses your meaning more clearly. $\quad$ (History feedback)

Avoid long sentences. Before you have control over sentence structure use a single sentence for each point. This will allow readers to see your argument better. (Business feedback)

In contrast, there was far greater emphasis on content in the feedback given to the writers of assignments in the hard sciences.

The main disadvantage of using this treatment is that dead cells may also be counted. (Biology feedback) 
Results from the original samples would give a better indication of the changes.

Present these in a table..

(Engineering feedback)

Respondents in different fields gave a different emphasis in their interviews (and in their feedback) to what they regarded as important in encouraging 'good writing' through written response. Humanities teachers, for example, wanted students to evaluate ideas and make connections between things they had read, while in the hard sciences teachers gave feedback which stressed the need for students to demonstrate an understanding of basic concepts of scientific methods and how experimental results is used as evidential support for conclusions. Again, however, these goals were seen as aspects of writing rather than something additional to it, as shown in the following excerpts:

I suppose my feedback focuses on trying to help them clearly state a claim or idea and then how they can develop it in an appropriate style. So, it's about encouraging clarity of thought and clearly defining a question to discuss.

(English)

I give feedback for two things. First, to make them think about their experiment, why they are doing it and the problems that they encounter. They never think of all of the steps. Second, is get them to write this in a formal English manner. Primarily of course I am dealing with the science but I am also trying to deal with their English. They have to go through the whole process from the logic of the model, the hypothesis, the analysis and then the discussion and that requires a certain English standard as well.

(Biology)

Logical presentation, putting thoughts together in ways recognised and approved as effective by the discipline, was a common thread in these interviews. For many tutors this was a question of focus and being able to lead an argument without too much deviation. 'Succinctness' and 'getting to the point' were often mentioned in this regard:

No I am not really focusing on the content. Content is important, of course but I want them to get to the point, what do they want to say? What is the key thing? You know, 
you write for a reason not you write because you want fill up 10 pages. You know, it's not very concise, there is a problem, not concise at all. (Economics)

I am looking a good logical framework, to show good scientific principles. This means producing work that it is concise, precise and develops good arguments. It also should bring something which shows scientific thinking and research.

\section{(Physics)}

Exactly what "concision" means to these respondents was not defined, however, nor was it clear how students were expected to come to understand it. Deciding what to include and exclude, what to elaborate and what to skim over, depends on an informed assessment of one's audience and what they know and need to know, and this is notoriously difficult for undergraduates to judge.

The feedback comments themselves largely attempt to support these efforts to develop effective argument skills, with each discipline taking trouble to stress what should be included, where it should be in the assignment, and how it should be expressed, as these examples illustrate:

More needed in the intro: what will you argue? How will you argue it?

(Engineering feedback)

You are trying too hard to demonstrate similarity between the concept of harmony in the culture and in drinking tea. Something is missing to link the preference for harmony and the concoction of tea. This has to be argued not assumed.

(History feedback)

This is the key idea that you should further discuss. Mention it above and develop it more here.

(Business feedback)

Overall, what these faculty teachers seemed to desire as an outcome of their feedback and teaching was for students to develop a conceptual understanding of the discipline which included both these ideational and rhetorical aspects. These two extracts capture this goal well: 
The biggest challenge for us with feedback is to point out why their writing doesn't make sense even if it presents the right information. They can't think in the right way.

(Biology)

Well, when I think about giving feedback, I reflect on what I received as a student as I would think that the comments didn't reflect the amount of work I put into the project. So when I give feedback, I break it down, I give them feedback on the overall impact of the piece, the argument in an essay. Then I would look at whether they got the basic structure, and then look at content. What about historical content? Is it accurate? Has it been persuasively argued? Are they thinking the right way?

(History)

Feedback, whether focused on argument, language or 'content', had a clear goal for many of these tutors and it is a goal which contrasts with a great deal of teaching in EAP classes: it seeks to encourage learners to 'think in the right way'.

\section{Provision of feedback}

While I have quoted some of the many interview statements by tutors concerning what they thought feedback might achieve, not all respondents actually provided a response to students' writing. While feedback is encouraged by the university Teaching and Learning Unit and by faculty committees, there is considerable variation in the extent to which tutors employed it and many of the texts just contained ticks, question marks and a grade.

Some subject tutors, particularly those in the arts and business faculties, stated that they frequently spent considerable time reading student assignments, often up to an hour for each paper. They further underlined their faith in the efficacy of feedback by stating that they often supplemented written comments with follow-up tutorials or ad hoc class sessions, as in these quotes:

I write comments in their papers and take examples to put up on the visualizer as part of the lecture. Then I walk them through. I show them examples of good and 
bad ones. We tend to talk about the organisation and writing. The students seem to like this and we get plenty of questions.

If they ask for feedback, I ask them to come to see me because I can sit down and ask them what they think. It's easier to explain things verbally and show them the piece of work and say look here you can see this, this and this. What should be in it and how things link up. I try to do that way.

(Economics)

These tutors recognised that their feedback might be more effective for some students if it was conveyed in more than one way, and particularly if it allowed for face to face interaction and questioning. This kind of dialogue is familiar to most writing teachers. It draws on the Vygotskian concept of scaffolding and how dialogic feedback between teacher and student can enable the student writer to develop both a text and writing abilities. The interactive nature of the conference allows tutors to clarify particular expectations and resolve any ambiguities, but it also offers opportunities to respond to the fact they are working with second language students who often have particular cultural and writing needs. Hong Kong students, particularly in their first year at university, feel inhibited about engaging informally with authority figures and these face to face conferences were typically conducted as group sessions or in-class tutorials to avoid students passively and unreflectively incorporating the teacher's suggestions into their work.

Moving beyond teacher feedback, several tutors mentioned that they organised peer response groups, both to relieve themselves of marking loads and to provide students with additional learning experiences:

This year, I am actually allowing students to give feedback to one another. In my Company Law class, I created a class blog and the writing assignment for each student was that they had to write a post each week responding to the group member who wrote the essay. So, everyone wrote a paper and got nine 
responses to it from their classmates. So, it's an ongoing class discussion and all online.

(Business Studies)

The reason I asked them to do this was by critiquing other people's work they also learn to critique their own. It's always easier to see problems in the work of other people and hopefully they learn to read their own work in a more critical way.

(History)

While writing teachers are perhaps less enamoured of peer review than in the past (e.g. Vilamill \& de Guerrero, 2006), it is becoming more widely used in university teaching generally, although with varying effectiveness (Berg et al, 2006). From a socio-cognitive perspective, peer review can be seen as a formative developmental process which gives writers opportunities to discuss their texts and discover others' interpretations of them. When sensitively managed by teachers who understand students' needs, individual relationships and the strengths and challenges of the approach, peer response has the potential to benefit both reviewers and writers.

In contrast to those who gave, and even extended the ways they provided, feedback to students, other tutors required no drafts and gave no feedback. These quotes are representative of this group: In fact they don't need to submit any drafts before their final submission. There is no such system really in Civil for students drafting and feedback. They might talk to us informally before they write to ask whether we should include this, how to arrange that. But it isn't compulsory.

(Engineering)

Actually I don't ask for a draft. Their report is an assignment and they are graded on this. If we give them a chance to write a draft, if we correct a draft, we are just giving a grade to our own work. We don't write their exams for them so why write their reports? (Engineering) 
In many courses there was no systematic mechanism for supporting students through feedback on written work, although many participants said they often responded informally to email or office hour requests for advice on written assignments.

Other tutors, especially in the sciences, delegated feedback to teaching assistants, as mentioned here:

Students have access to postgraduate demonstrators. I think it is the students' initiative whether they use them and it's obvious they are the ones which do much better, I think they obviously had some input.

(Biology)

They go to the postgraduates first and then to me if necessary. If the students send them their drafts then the demonstrator will give them feedback. But this isn't compulsory. It's up to them.

(Chemistry)

In Hong Kong it is common for postgraduate students in science and engineering to be assigned teaching roles as a condition of their government scholarship. These duties often involve assisting students with experiments in laboratory projects, but the TAs also find themselves conducting tutorials, marking assignments and advising students on their assessed reports. Undergraduate students themselves find this kind of delegation a dereliction of their tutors' responsibilities. This is often exacerbated by the fact that the TAs are largely students from the Chinese mainland whose grasp of academic English is often no better than their own. The message students understand from this is that their professors do not regard disciplinary writing as important (Hyland, submitted).

This lack of response to students' writing not only misses an opportunity for targeted instruction, but contrasts quite markedly with the practice of EAP teachers at the university. All EAP course learning outcomes place an emphasis on writing and all courses provide feedback on a drat, often followed by a tutorial or peer group consultation. Teachers recognise that students are unfamiliar with university assignments and are often quite anxious about what is expected. Finding sources, 
paraphrasing, referencing, plagiarism, and so on present serious challenges to them and individual feedback can provide crucial scaffolding as they acquire basic competencies.

\section{Value of feedback}

One set of questions in the interviews concerned tutors' beliefs about the value of feedback in contributing to learning and writing development. We have seen that almost all respondents acknowledged the importance of writing to students and many recognised its value in learning disciplinary concepts. There were, however, variations in how effective they thought feedback might be in contributing to student learning. For some, setting writing assignments was a means of ensuring that students had fulfilled the requirements of the course by demonstrating knowledge and understanding. Again, this view was more common among the teachers working in the hard sciences where knowledge acquisition is often more important than argument and interpretation (Nuemann, Parry \& Becher, 2002). For them, feedback had doubtful significance:

I don't think it's very helpful, especially if it's approaching the end of the course, they care about the grade. So, when something is done, they don't care about it anymore. They will just forget they ever did it. (Biology)

I don't think it makes a lot of difference to be honest. It all depends on the students. Some students will come and talk about it and will go away and change it. Some students seem not to care too much. I guess if the students thought it was helpful more of them would ask for feedback.

\section{(Engineering)}

Interestingly, the science and engineering assignments contained about half the feedback comments than those given on humanities and social science texts and significantly more ticks and other symbols. It is difficult to escape the sense that, in many cases, these student texts have been hurriedly checked, rather than carefully read, and this is not lost on students themselves, who often express their frustration at the feedback they receive in these disciplines (Author, submitted). 
Several respondents did not regard students' acquisition of disciplinary writing conventions as their responsibility, or saw it as something which simply improved along with subject knowledge:

How helpful is the written feedback for improving students work? I've no idea. I don't teach them how to write. They go to academic writing classes I think, and should get ideas about writing from the readings we give them. I don't think my feedback would help them to write. (Engineering)

Even those tutors who gave feedback and regarded it as an important part of their role were often ambivalent about its effects. While they wanted to believe that there was an improvement in the performance of their students, they often struggled to find it:

Perhaps it is reflected in how they did in the exam after they had the feedback on the essays, but I am not sure I can say for sure. I like to think that feedback is useful for their writing, but I've not quantified that with my students. Anyway, each student is different and you don't know them well enough to find out what works with each one. It can be difficult to help.

(Economics)

I think that it's hard to see the effects within the semester because this is not a writing course, we are not here to teach writing. So I think to improve it takes a long time. But if you only have the students for one semester, it's quite unusual to see a very marked improvement because it takes a long time, Even for us, it took years to learn how to write.

(History)

These tutors tended to see writing as a complex and multi-layered aspect of disciplinary learning which transcended the simple regurgitation of knowledge for assessment purposes. There is a recognition here that students' immediate need to produce texts which are regarded as competent and successful by tutors includes being self-sufficient in constructing acceptably accurate academic prose. Feedback is an important aspect of this process but one which requires commitment and time. Time is a precious and rare commodity in the modern university, however, and many 
respondents mentioned the need to adjust to institutional priorities when deciding how much support to give students with their writing. Feedback, and teaching itself, involved compromises with other demands and both were often cited as being weakened by the university climate: I am teaching 5 different courses this semester. Two in Shanghai, one in Cyberport and two here! Altogether about 350 to 400 students this semester alone. It's impossible for me to sit down with every single one. Even if it is 5 minutes per student, that would be 2000 minutes which is, you know, 300 hours, I mean it is impossible.

(Business Studies)

I don't think many teachers give feedback, not because they don't want to, but they are just overworked in the Business Faculty. We have a huge teacher-student ratio and we just can't give quality feedback to every single student in a class of 200, you know.

(Business Studies)

Where time is in short supply, teaching, and particularly opportunities to provide feedback, take a back seat to more visible and valued aspects of the academic's role. This historian summed up the dilemma expressed by many respondents in my sample:

We shouldn't fool ourselves. We need to understand that this is a research university where the expectations are quite clear. Research is at the top. Teaching is number two and administration is number three. Some of us sometimes feel that administrative work is number two and teaching is at the very bottom. We don't have as much time to help students as we would like.

(History)

The sense that many EAP teachers have of working in a context in which they are acting alone to overcome students' puzzlement and frustration in mastering the mysteries of academic literacies is therefore not altogether misplaced. This is, however, often not a matter faculty indifference, but of expediency. 


\section{Discussion: Some observations and implications}

This has been a small study of academic perceptions on second language writing and feedback in one particular, perhaps even unique, context and so it is difficult to generalize too far from these teachers' comments. However, because most prior research has studied writing classrooms and writing teacher's feedback, the present study helps to illuminate something of the communicative demands that disciplinary writing make on L2 newcomers. In particular, focusing on faculty teachers' perspectives shifts attention to the importance of the reader in writing (Hyland, 2011) and the need for writers to understand and incorporate an audience for their texts, addressing those who will judge the learning that has occurred. The findings therefore have relevance for both the research on L2 writing feedback and for the writing-to-learn dimension of L2 writing. For the former, it moves studies beyond the texts produced for teachers in the writing classroom and away from concerns with accuracy and error correction to an understanding of faculty expectations and practices. For the latter it contributes to our understanding of the tasks and expectations which surround students attempts to advance their expertise in academic content areas by writing themselves into their disciplines.

Overall, these interviews suggest that this audience of faculty teachers generally wants to see students write in disciplinary approved ways as a means of demonstrating their acculturation into the field and that teacher feedback is coloured by these understandings. Moreover, the transcripts indicate that faculty teachers seem to recognise, often implicitly, the intimate connections between content and its appropriate disciplinary expression, yet their feedback only infrequently seeks to support students towards this same recognition.

One important finding, and one which contrasts with a great deal of previous research on written feedback, is the relative lack of attention given to accuracy by these faculty teachers. Error correction has been a staple of research into feedback in second language writing for at least 20 years (e.g Bitchener, 2009; Bitchener \& Knoch, 2008; Ferris, 2006) yet these data indicate that faculty teachers are more concerned that their students can produce a disciplinary effective argument than whether they can produce grammatical sentences. They are interested in seeing if students can 
"think in the right way" and largely believe that students will come to learn their subject and its conventional discourse in tandem. There is a recognition in these transcripts that form and content are two sides of the same coin and this chimes with a great deal of EAP instruction at university. Like many writing teachers, they see the purpose of writing instruction as not to reinforce language structures but to help students to mean in ways which are recognised and valued by readers in their disciplines (Hyland, 2004; Wingate, 2012).

Previous studies have established the importance of corrective feedback to second language students, who often have strong expectations that teachers will notice and comment on the accuracy of their work in their feedback, being frustrated if this does not happen (Ferris,1995; Ferris \& Roberts 2001; Hyland, F. 1998). Faculty teachers, however, do not see assisting students with their language difficulties as their job. The subsequent lack of attention faculty give to errors can therefore unsettle freshman students, especially those who have emerged from school cultures such as those in Hong Kong where teachers are error-focused in their feedback (e.g. Lee, 2008). In this regard, it might be productive for teachers to seriously consider Truscott's (2007) controversial advice to move students away from what is often an obsessive preoccupation with correctness in their writing and the expectation that teachers will address errors in their feedback. More generally, we might see that the 'grammar correction debate', which has exercised feedback researchers for so long, is actually of marginal importance where students are being asked to demonstrate and consolidate learning in university contexts; that is, where they are Writing-to-Learn both content and how to talk about it.

Another key point which emerges from these interviews concerns the importance of discipline in mediating the beliefs, expectations and practices which surround writing in the university and which selectively activate knowledge. While faculty teachers may be exercising their personal preferences when giving feedback, they are also seeking to accomplish disciplinary-specific pedagogic goals. They are, in other words, working within academic cultures which, while being fluid and nondetermining, foreground certain taken-for-granted conceptions of argument and beliefs about what counts as good writing (Hyland, 2004). Their decisions when giving feedback are therefore 
influenced by the ideologies and expectations of their academic community and acquired through their own literacy experiences as disciplinary members. Needless to say, these decisions are likely to differ from those of writing teachers whose feedback expresses their own literacy experiences and training. While the interests and roles of faculty and writing teachers are not the same, their different ideologies contribute to different understandings about writing which might be usefully made explicit. There is a strong argument here for writing teachers to establish greater collaboration with discipline teachers to identify the arguments, expressions and expectations of the discipline.

But while students are required to write well to reconstruct disciplinary knowledge and to communicate in professional contexts in the future, they are often unaware of the valued conventions and practices of their communities. Some teachers in this study claimed to actively encourage this learning through their written feedback and follow-up sessions, but others questioned the effectiveness of feedback and believed that student motivation will eventually help them reach this understanding. For some of my informants writing is seen as something to be picked up through reading in the subject rather than by explicit instruction. All too often, subject teachers consider academic literacy as a naturalised, selfevident and non-contestable way of participating in their discipline, treating writing conventions as common sense knowledge and failing to provide the kind of support that students need to acquire these rhetorical understandings (e.g. Lea \& Street, 2000).

Students are, it seems, rarely provided with a means of conceptualizing the epistemological frameworks of their fields and often see their success or failure as dependent on the quirks of individual tutors (Ivanic et al, 2000; Weaver, 2006). Ultimately, responsibility for disciplinary writing instruction often rests with writing teachers. It becomes our responsibility to make the connections between writing and knowledge explicit to learners and for this reason it is important that we have some understanding of the expectations of faculty teachers to best support students in acquiring the key features of disciplinary writing. 


\section{Conclusion}

Often EAP teachers have a vague sense that the feedback their students get from subject tutors, when they get any at all, tends to be prescriptive, cursory and largely focused on content, thus conveying the idea that writing conventions are absolute, generic and obvious. Many of the tutors interviewed here, however, recognised that feedback could encourage revision and help develop both subject and writing development. But while they may receive considerable support with assignments from subject tutors who recognise the importance of writing conventions and see their discipline in its discourses, these interviews show that students cannot always depend on this. In the absence of such support, EAP writing teachers are often the only resources students have in acquiring a better understanding of writing and its relation to disciplinary practices.

In many cases, then, it falls to writing teachers to help students look at writing in a different way, seeing linguistic forms as not merely arbitrary, instrumental and autonomous, just something to 'get right', but as fundamental to both writing and to thought itself. An important part of this process might involve teachers in gaining a greater awareness of students' experiences of writing outside the English class through the study of faculty feedback. Needs analysis, the set of techniques for collecting and assessing information relevant to course design, has been a central element of writing instruction for many years, but rarely has it extended to considering the kinds of feedback given by subject teachers. This feedback is useful for a number of reasons, not least for what it tells us about the expectations faculty teachers have of student writing. These responses, shaped and constrained as they are by the possibilities made available by their disciplinary experiences, carry information about faculty writing practices, about subject teacher beliefs and about learner performance. In sum, they form a key part of the context of writing at university.

By considering this feedback as part of both students' experience of an immediate interaction with their tutors and an engagement with larger disciplinary forces, we might gain a wider understanding of student writing and insights into how best to teach it. 


\section{References}

Belcher, D. (Ed.). (2009). English for specific purposes in theory and practice. Ann Arbor, MI: University of Michigan Press.

Berg, I., Admiraal, W. \& Pilot, A. (2006). Peer assessment in university teaching: evaluating seven course designs. Assessment \& Evaluation in Higher Education, 31(1), 19-36.

Bitchener, J. (2008). Evidence in support of written corrective feedback. Journal of Second Language Writing, 17(2), 102-118.

Bitchener, J. \& Knoch, U. (2009). The relative effectiveness of different types of direct written corrective feedback. System, 37(2), 322-329.

Carless, D. (2006). Differing perceptions in the feedback process. Studies in Higher Education. $32(2), 219-233$.

Charles, M., Pecorari, D. \& Hunston, S. (Eds.). (2009). Academic writing: At the interface of corpus and discourse. London: Continuum.

Currie, P. (1993). Entering a disciplinary community: Conceptual activities required to write for one introductory university course. Journal of Second Language Writing, 2 (2), 101-117.

English, F. (2011) Student writing and genre: Reconfiguring academic knowledge. London: Continuum.

Ferris, D. (1995). Student reactions to teacher response in multiple-draft composition classrooms. TESOL Quarterly, 29(1), 33-53.

Ferris, D. (2006). Does error feedback help student writers? New evidence on the short- and longterm effects of written error correction. In K. Hyland \& F. Hyland (Eds.). Feedback in second language writing: Contexts and issues (pp. 81-104). Cambridge: Cambridge University Press.

Ferris, D. \& Roberts, B. (2001). Error feedback in L2 writing classes. How explicit does it need to be? Journal of Second Language Writing 10 (3), 161-18.

Gimenez, J. (2009). Beyond the academic essay: Discipline-specific writing in nursing and midwifery. Journal of English for Academic Purposes, 7 (3), 151-164.

Hattie, J. \& Timperley, H. (2007). The power of feedback. Review of Educational Research. 77 (1), $81-112$ 
Hirvela, A. (2011). Writing-to-learn in content areas: Research insights. In R.M. Manchón (Ed.), Learning-to-write and writing-to-learn in an additional language ( $\mathrm{pp}$ 37-60). Amsterdam: John Benjamins.

Hyland, F. (1998). The impact of teacher written feedback on individual writers. Journal of Second Language Writing, 7(3), 255-286.

Hyland, K. (2004a) Disciplinary discourses: Social interactions in academic writing. Ann Arbor, MI: University of Michigan Press.

Hyland, K. (2004b) Genre and second language writing. Ann Arbor, MI: University of Michigan Press.

Hyland, K. (2006) English for academic Purpose: An advanced resource book. London: Routledge. Hyland, K. (2009). Academic discourse. London: Continuum.

Hyland, K. (2011). Learning to write: Issues in theory, research and pedagogy. In R.M. Manchón (Ed.), Learning-to-write and writing-to-learn in an additional language (pp 17-36). Amsterdam: John Benjamins.

Hyland, K. (submitted). Student perceptions of hidden messages in teacher written feedback. Hyland, K. \& Bondi, M. (Eds.) (2006). Academic discourse across disciplines. Frankfort: Peter Lang.

Ivanic, R., Clark, R. \& Rimmershaw, R. (2000). What am I supposed to make of this? The messages conveyed to students by tutors' written comments. In M. Lea \& B. Stierer (Eds.), Student writing in higher education: New contexts. (pp 47-65). Buckingham, UK: Open University Press.

Krause, K.L., Hartley, R. James, R. McInnis, C. (2005). The first year experience in Australian universities: Findings from a decade of national studies. http://www.griffith.edu.au/data/assets/pdf_file/0006/37491/FYEReport05.pdf (accessed 4/9/2012). 
Lea, M. and Street, B. V. (2000) 'Student writing and staff feedback in higher education', in M. Lea and B. Stierer (Eds.), Student writing in higher education: New Contexts (pp 32-46). Buckingham: SRHE and Open University Press.

Lee, I. (2008). Understanding teachers' written feedback practices in Hong Kong secondary classrooms. Journal of Second Language Writing. 17(2), 69-85.

Leki, I. (2007). Undergraduates in a second language: challenges and complexities of academic literacy development. New York, NY: Lawrence Earlbaum.

Lillis, T. (2001) Student writing: Access, regulation, desire. London: Routledge.

Manchón, R.M. (Ed.). (2011a). Learning-to-write and writing-to-learn in an additional language. Amsterdam: John Benjamins.

Manchón, R.M. (2011b). Situating the learning-to-write and writing-to-learn dimensions of L2 writing. In R.M. Manchón (Ed.), Learning-to-write and writing-to-learn in an additional language (pp. 3-14). Amsterdam: John Benjamins.

Nesi, H. \& Gardner, S. (2011). Genres across the disciplines. Student writing in Higher education. Cambridge: Cambridge University Press.

Nuemann, R., Parry, S. \& Becher, T. (2002). Teaching and learning in their disciplinary contexts: a conceptual analysis. Studies in Higher Education. 27 (issue), 405-13.

Ortega, L. (2011). Reflections on the learning-to-write and writing-to-learn dimensions of second language writing. In In R.M. Manchón (Ed.), Learning-to-write and writing-to-learn in an additional language (pp 237-250). Amsterdam: John Benjamins.

Polkinghorne, D. (1995) Narrative configuration in qualitative analysis, Qualitative Studies in Education, 8 (1), 5-23.

Price, M., Handley, K., Millar, J. \& O’Donovan, B. (2010). Feedback: all that effort, but what is the effect? Assessment and Evaluation in Higher Education, 35 (3), 277-289.

Ravelli, L. J. \& Ellis, R. A. (eds.) (2004), Analyzing Academic Writing, Continuum.

Sternglass, M. (1997). Time to know them: a longitudinal study of writing and learning at the college level. Mahwah, NJ: Lawrence Earlbaum. 
Truscott, J. (2007). The effect of error correction on learners' ability to write accurately. Journal of Second Language Writing, 16(4), 255-272.

Truscott, J. (2009). Arguments and appearances: a response to Chandler. Journal of Second Language Writing, 18, 59-60.

Truscott, J. \& Hsu, A. Y.P. (2008). Error correction, revision, and learning Journal of second Language Writing. 17(4), 292-305.

Villamil, O. \& de Guerrero, M. (2006). Sociocultural Theory: A framework for understanding sociocognitive dimensions of peer feedback. In K. Hyland \& F. Hyland (Eds.). Feedback in second language writing: Contexts and issues (pp 23-41). Cambridge: CUP.

Wardle, E. (2009). "Mutt genres" and the goal of FYC.: Can we help students write the genres of the university? College Composition and Communication, 60 (4), 765-89.

Weaver, M. (2006). Do students value feedback? Student perceptions of tutors' written responses. Assessment \& Evaluation in Higher Education, 31 (3), 379-394.

Wingate, U. (2012). Using Academic Literacies and genre-based models for academic writing instruction: A ‘literacy’ journey Journal of English for Academic Purposes, 11 (1), 26-37 